\title{
Формирование наностержней GaN в монодисперсных сферических мезопористых частицах кремнезема
}

\author{
() Е.Ю. Стовпяга, Д.А. Курдюков, Д.А. Кириленко, В.Г. Голубев \\ Физико-технический институт им. А.Ф. Иоффре Российской академии наук, \\ 194021 Санкт-Петербург, Россия \\ E-mail: kattrof@gvg.ioffe.ru
}

Поступила в Редакцию 3 марта 2020 г.

В окончательной редакции 10 марта 2020 г.

Принята к публикации 10 марта 2020 г.

\begin{abstract}
В монодисперсных сферических мезопористых частицах кремнезема (МСМЧК) посредством высокотемпературного отжига из прекурсора $\mathrm{Ga}_{2} \mathrm{O}_{3}$ синтезированы наностержни $\mathrm{GaN}$ диаметром от 15 до 40 нм и длиной от 50 до 150 нм. Разработана методика удаления темплата посредством травления частиц МСМЧК/GaN в $\mathrm{HF}$, позволяющая получать индивидуальные наностержни GaN. Обнаружено, что размер наностержней $\mathrm{GaN}$ значительно превосходит размеры пор МСМЧК (диаметр $\sim 3$ нм, длина $\sim 10$ нм). Предложен возможный механизм формирования наностержней $\mathrm{GaN}$ и перераспределения вещества внутри композитных частиц MCMЧК/GaN посредством поверхностной диффузии молекул газообразных продуктов реакций в порах и диффузии атомов $\mathrm{Ga}$ и $\mathrm{N}$ в аморфном кремнеземе.
\end{abstract}

Ключевые слова: GaN, мезопористый кремнезем, наностержни, темплатный синтез.

DOI: 10.21883/FTP.2020.07.49508.9387

\section{1. Введение}

В последние десятилетия сохраняется большой интерес к получению и исследованию полупроводниковых наноматериалов различной морфологии, так как они обладают отличными от массивного материала электрическими, транспортными, механическими и оптическими свойствами $[1,2]$. В частности, наностержни $\mathrm{GaN}$ перспективны для различных областей микро-, нано-, оптоэлектроники и нанофотоники $[3,4]$. Стержневидная форма кристаллов характерна для $\mathrm{GaN}$, и их рост в направлении гексагональной оси $c$ происходит быстрее, чем вдоль осей $a$ и $b[5,6]$. Для получения наностержней $\mathrm{GaN}$ используются различные методы: газофазная эпитаксия $[7,8]$, лазерная абляция $[9,10]$, молекулярнопучковая эпитаксия $[11,12]$, плазмохимическое газофазное осаждение [13] и др. Существуют различные механизмы формирования и роста наностержней $\mathrm{GaN}$, которые зависят от способа их синтеза и параметров процесса $[14,15]$.

Одним из направлений получения нанокристаллитов $\mathrm{GaN}$ является синтез материала в цилиндрических мезопорах кремнеземов типа МСM-41 [16] и SBA-15 [17]. Пространственные ограничения роста кристаллитов различной формы обусловливаются диаметром и длиной мезопор, а также размером и формой частиц темплата. Так, в случае МСМ-41 в порах получаются наночастицы $\mathrm{GaN}$ размером в единицы нанометров $(\sim 3 \mathrm{Hм})[18]$, а в случае SBA-15 - наностержни размером $7 \times 50$ нм [17]. Несмотря на активное изучение механизмов роста кристаллов нитрида галлия, в литературе практически не исследованы механизмы формирования наноразмерных форм $\mathrm{GaN}$ в пористых матрицах.
Особое место среди пористых кремнеземов занимают монодисперсные сферические мезопористые частицы кремнезема (МСМЧК), имеющие внутреннюю систему цилиндрических наноканалов одинакового диаметра (3 нм) объемом до $60 \%$ от объема частиц [19-21]. На основе МСМЧК ранее нами получены нанокомпозитные частицы, содержащие оксиды [22], металлы [23], полупроводниковые материалы [24], углеродные наноточки [25]. При синтезе веществ в монодисперсных частицах одинаковой формы, обладающих идентичной структурой пор, химические и физические процессы протекают одинаково, поэтому МСМЧК идеально подходят в качестве модельного объекта (нанореактора) для изучения механизмов роста анизотропных кристаллов в кремнеземной матрице.

В настоящей работе обсуждается возможный механизм формирования наностержней $\mathrm{GaN}$ в МСМЧК в процессе высокотемпературного гетерогенного синтеза из газофазного и твердофазного прекурсоров. Образующиеся наностержни $\mathrm{GaN}$ имеют размер, значительно превышающий размер мезопор темплата. Процесс роста крупных наностержней $\mathrm{GaN}$ за счет исчезновения мелких, вероятно, обусловлен понижением общей энергии системы и происходит за счет диффузии атомов галлия и молекул $\mathrm{Ga}_{2} \mathrm{O}$ внутри МСМЧК. Проведены морфологические и структурные исследования полученных материалов.

\section{2. Методика эксперимента}

Нанокомпозитные частицы МСМЧК/GaN синтезировали согласно методике, описанной в работе [26]. МСМЧК диаметром $210 \pm 20$ нм, имеющие цилин- 
дрические поры диаметром $3.1 \pm 0.2$ нм и длиной 10-15 нм [19-21,27], заполняли расплавом кристаллогидрата $\mathrm{Ga}\left(\mathrm{NO}_{3}\right)_{3} \cdot 8 \mathrm{H}_{2} \mathrm{O}$. Затем образцы высушивали при температуре $400 \mathrm{~K}$ с последующим отжигом при $T=800 \mathrm{~K}$ в течение 3 ч для разложения нитрата до оксида $\mathrm{Ga}_{2} \mathrm{O}_{3}$. Степень заполнения мезопор $\mathrm{Ga}_{2} \mathrm{O}_{3}$ составила 40 об.\% от объема пор [26]. Последующий отжиг МСМЧК, заполненных оксидом галлия, проводили в атмосфере аммиака (1 бар) при температуре $1300 \mathrm{~K}$ в течение 20 ч для получения нитрида галлия, внутри частиц:

$$
\mathrm{Ga}_{2} \mathrm{O}_{3}(s)+2 \mathrm{NH}_{3}(g) \rightleftarrows 2 \mathrm{GaN}(s)+3 \mathrm{H}_{2} \mathrm{O}(g) .
$$

Для травления материала темплата $\left(a-\mathrm{SiO}_{2}\right)$ навеску нанокомпозитных частиц МСМЧК/GaN помещали в раствор плавиковой кислоты (40 масс.\% HF) на 2 ч. Затем нерастворившийся материал (вещество-наполнитель) отделяли центрифугированием с последующей промывкой деионизованной водой и редиспергировали под действием ультразвука.

Микроскопические исследования выполнялись с помощью просвечивающего электронного микроскопа (ПЭМ) JEM-2100F, Jeol, Япония. Рентгеноспектральный микроанализ (РСМА) проводили с использованием энергодисперсионного рентгеновского спектрометра Oxford Instruments INCA, встроенного в ПЭМ. Распределение частиц по размерам регистрировали методом динамического светорассеяния (ДСР) на приборе Malvern Zetasizer Nano при температуре 298 K. Рамановские спектры были измерены при комнатной температуре на спектрометре Horiba Jobin Yvon T64000 с использованием в качестве источника излучения второй гармоники $\mathrm{Nd}$ : YAG-лазера $(\lambda=532 \mathrm{HM})$, плотность возбуждения на поверхности образца не превышала $P=2$ кВт/см².

\section{3. Результаты и обсуждение}

При исследовании материала, полученного после растворения материала темплата, методом ПЭМ обнаружено, что он представляет собой наностержни диаметром от 15 до 40 нм и длиной от 50 до 150 нм (рис. 1), состоящие, по данным рамановской спектроскопии (рис. 2), из нанокристаллического гексагонального $\mathrm{GaN}[26,28,29]$. По данным атомно-силовой [26] и просвечивающей электронной (рис. 3) микроскопии, на поверхности композитных частиц МСМЧК/GaN массивный нитрид галлия отсутствует. В то же время наблюдаемые размеры наностержней $\mathrm{GaN}$ значительно превышают размеры пор в МСМЧК (диаметр 3 нм, длина 10-15 нм [19-21,27]).

Размер объектов, наблюдаемых на рис. 1, коррелирует с размером области когерентного рассеяния $\mathrm{GaN}$ $(29$ нм), который был определен посредством обработки рентгеновской дифрактограммы композитных частиц МСМЧК/GaN методом Ритвельда [26]. Кроме того, включения размером в несколько десятков нанометров, содержащие, по результатам РСМА, атомы галлия, наблюдаются на ПЭМ изображениях высокого разрешения

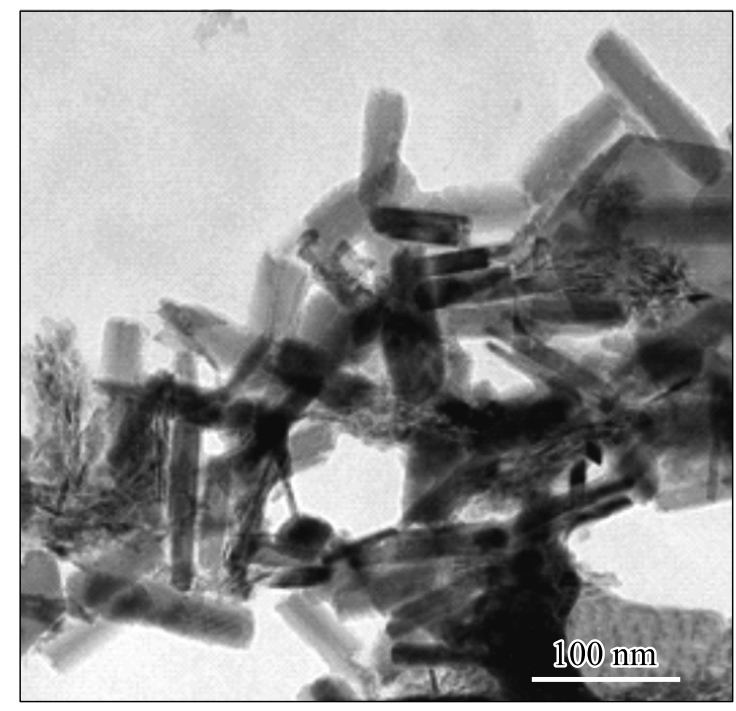

Рис. 1. ПЭМ изображение наностержней $\mathrm{GaN}$.

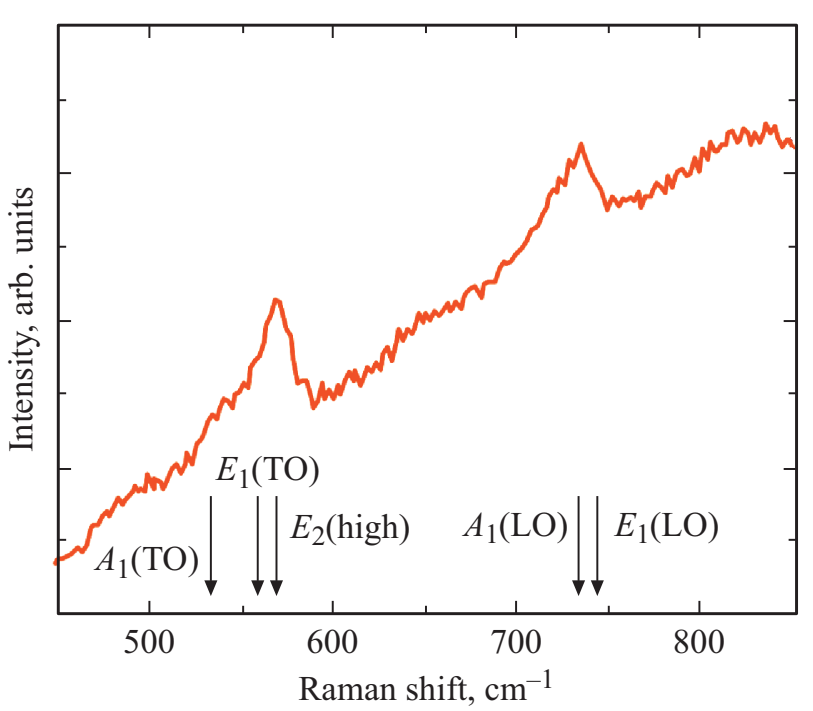

Рис. 2. Рамановский спектр наностержней GaN. Стрелками обозначено положение раман-активных фононных мод гексагонального $\mathrm{GaN}$.

(ВРПЭМ) композитных частиц (рис. 3). По данным ДСР, средний гидродинамический размер наностержней $\mathrm{GaN}$ составляет $160 \pm 25$ нм (рис. 4), что согласуется с данными ПЭМ (рис. 1 и 4, см. вставку). На основании приведенных выше результатов можно утверждать, что наностержни образовались внутри МСМЧК во время высокотемпературного гетерогенного синтеза $\mathrm{GaN}$ из прекурсора $\mathrm{Ga}_{2} \mathrm{O}_{3}$, введенного в мезопоры. После удаления темплата наностержни $\mathrm{GaN}$ диспергируются в водной дисперсионной среде.

Рассмотрим подробно возможный механизм формирования и роста кристаллитов $\mathrm{GaN}$ в МСМЧК. Предположим, что сначала в мезопорах образовались частицы средним диаметром $\sim 3$ нм, как было показано ранее 

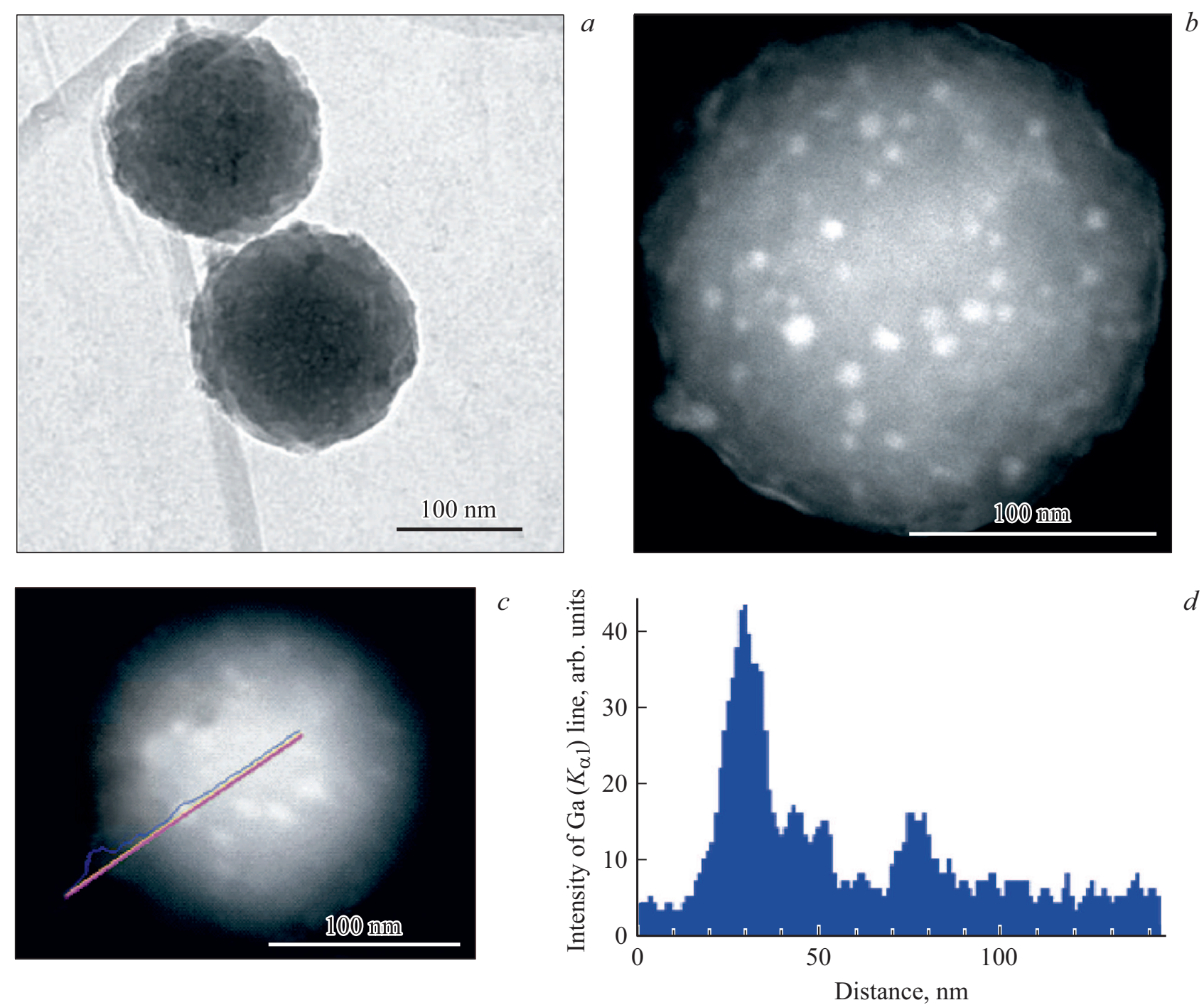

Рис. 3. ПЭМ $(a)$ и ВРПЭМ $(b, c)$ изображения нанокомпозитных частиц MCМЧК/GaN. $d-$ профиль распределения галлия, полученный методом РСМА с одной частицы.

на примере углеродных наноточек [25]. Чем меньше размер частицы, тем больше ее поверхностная энергия на единицу объема и выше химический потенциал. Разность химических потенциалов $\Delta \mu$ у частиц $\mathrm{GaN}$ разного размера способствует массопереносу вещества от маленьких частиц к крупным. Основной причиной массопереноса является стремление системы к уменьшению поверхностной энергии благодаря уменьшению количества маленьких частиц и переход в энергетически более выгодное состояние. Понижение общей энергии системы в процессе увеличения наностержней в размере и снижение их $\mu$ является термодинамически выгодным процессом [30,31] и описывается формулой ГиббсаТомпсона [32]:

$$
\Delta \mu=\mu_{r}-\mu_{\infty}=\frac{2 \sigma_{\mathrm{GaN}-\mathrm{SiO}_{2}} V_{\mathrm{GaN}}}{3 r},
$$

где $\mu_{r}$ и $\mu_{\infty}-$ химические потенциалы компонента в наночастице радиусом $r$ и в частице бесконечного размера соответственно, $\sigma_{\mathrm{GaN}_{-} \mathrm{SiO}_{2}}$ - поверхностное натяжение на границе раздела $\mathrm{GaN}-\mathrm{SiO}_{2} ; V_{\mathrm{GaN}}$ - мольный объем GaN.

B порах МСМЧК при наличии наностержней даже с небольшим разбросом размеров происходит массоперенос вещества от мелких наностержней (вплоть до их полного исчезновения) к более крупным. Описанный процесс будет происходить до тех пор, пока скорость исчезновения мелких наностержней станет незначительной и скорость массопереноса будет пренебрежимо малой (система приблизится к термодинамически равновесному состоянию).

Внутри МСМЧК возможны два пути переноса вещества. Во-первых, в мезопорах МСМЧК молекулы газообразных компонентов могут перемещаться посредством поверхностной диффузии. Во-вторых, при температуре синтеза $1300 \mathrm{~K}$ аморфный кремнезем, образующий МСМЧК, постепенно размягчается, пористая структура 


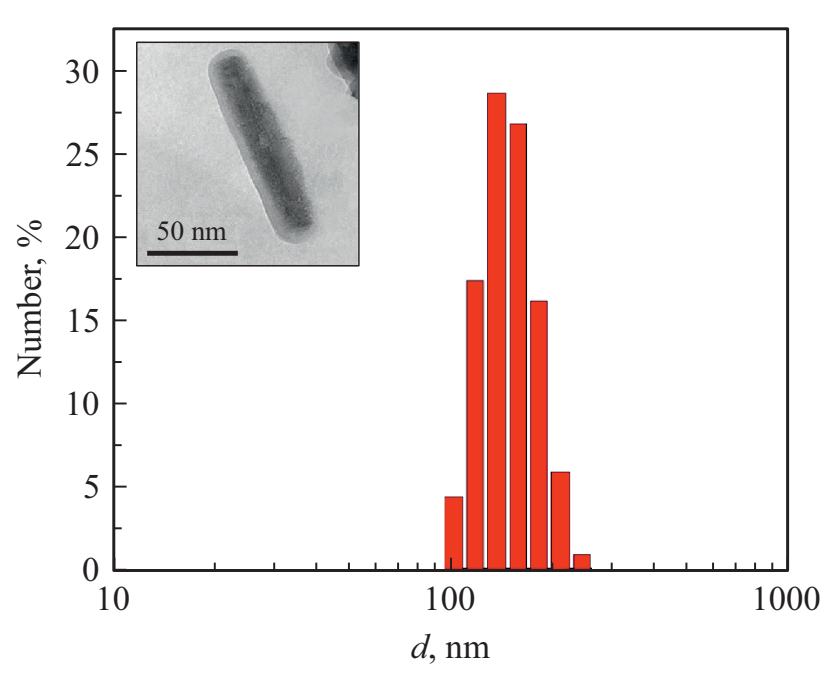

Рис. 4. Распределение размеров наностержней $\mathrm{GaN}$, измеренное методом ДСР. На вставке приведено увеличенное ПЭМ изображение наностержня $\mathrm{GaN}$.

внутри частиц исчезает, и поэтому основным способом массопереноса становится диффузия атомов Ga и $\mathrm{N}$ в аморфном кремнеземе.

Рассмотрим массоперенос вещества через газовую фазу. В результате терморазложения аммиака (давление 1 бар), согласно реакции $2 \mathrm{NH}_{3} \leftrightarrow \mathrm{N}_{2}+3 \mathrm{H}_{2}$, образуется водород (равновесное давление $\mathrm{H}_{2}$ при температуре синтеза - сотни миллибар [33,34]), который реагирует с оксидом галлия [35,36]:

$$
\mathrm{Ga}_{2} \mathrm{O}_{3}(s)+2 \mathrm{H}_{2}(g) \leftrightarrow \mathrm{Ga}_{2} \mathrm{O}(g)+2 \mathrm{H}_{2} \mathrm{O}(g) .
$$

Рассчитанная энергия Гиббса реакции (2) $\Delta G_{1300}^{0}=$ $=+95$ кДж/моль, соответствующая константа равновесия $K_{p}=p_{\mathrm{H}_{2} \mathrm{O}}^{2} p_{\mathrm{Ga}_{2} \mathrm{O}} / p_{\mathrm{H}_{2}}^{2}=10^{-4}$. При давлении водорода 100 мбар равновесное давление продукта реакции (2) $\mathrm{Ga}_{2} \mathrm{O}$ составляет 10 мбар, т.е. реакция (2) действительно может протекать в порах частиц кремнезема при синтезе $\mathrm{GaN}$. Ранее подобный процесс перехода $\mathrm{Ga}_{2} \mathrm{O}_{3}$ в $\mathrm{Ga}_{2} \mathrm{O}$ регистрировали авторы работ $[35,37]$. По-видимому, $\mathrm{Ga}_{2} \mathrm{O}$ переносится в мезопорах с последующим образованием нитрида галлия $[35,36]$ согласно следующему уравнению реакций:

$$
\begin{aligned}
\mathrm{Ga}_{2} \mathrm{O}(g)+2 \mathrm{NH}_{3}(g) & \leftrightarrow 2 \mathrm{GaN}(s)+\mathrm{H}_{2} \mathrm{O}(g)+2 \mathrm{H}_{2}(g), \\
\Delta G_{1300}^{0} & =-98 \text { кДж/моль. }
\end{aligned}
$$

Посредством реакций (2), (3) происходит массоперенос и укрупнение наностержней GaN. Образование газообразного Ga при температуре $1300 \mathrm{~K}$ мало вероятно вследствие низкого давления его паров (10 ${ }^{-7}$ бар) [38], поэтому $\mathrm{Ga}(g)$ не участвует в массопереносе и нами не рассматривался. Мы полагаем, что на данном этапе в трехнанометровых порах МСМЧК могут формироваться нанокристаллиты $\mathrm{GaN}$ диаметром до 3 нм и варьируемой длиной.
Наряду с образованием $\mathrm{GaN}$ из $\mathrm{Ga}_{2} \mathrm{O}_{3}$ уже сформировавшиеся наночастицы или наностержни $\mathrm{GaN}$ частично могут превращаться в $\mathrm{Ga}_{2} \mathrm{O}$ за счет обратной реакции (3). $\mathrm{Ga}_{2} \mathrm{O}$ переносится и реагирует с $\mathrm{NH}_{3}$ (которого в системе в избытке), образуя $\mathrm{GaN}$ (3), вблизи поверхности более крупных наностержней $\mathrm{GaN}$, таким образом увеличивая их размер. Подобные газотранспортные реакции (прямая и обратная реакции (3)) характерны для бинарных соединений различного состава [39]. Образующиеся в ходе реакции синтеза $\mathrm{GaN}$ из $\mathrm{Ga}_{2} \mathrm{O}_{3}$ (1) пары воды выступают в качестве транспортирующего агента.

При температуре $1300 \mathrm{~K}$ пористый кремнезем размягчается [40]. Поры МСМЧК закрываются, и последующий массоперенос вещества происходит за счет диффузии атомов $\mathrm{Ga}$ и $\mathrm{N}$ в аморфном $\mathrm{SiO}_{2}$. Сформировавшийся на предыдущем этапе $\mathrm{GaN}$ переносится к более крупным наностержням и так, в соответствии с уравнением Гиббса-Томпсона, вплоть до формирования стержней размером, соизмеримым с размером самих МСМЧК. При температуре $1300 \mathrm{~K}$ коэффициент диффузии атомов $\mathrm{Ga}$ и $\mathrm{N}$ в $\mathrm{SiO}_{2}$ составляет $D(\mathrm{Ga}) \sim 5 \cdot 10^{-11} \mathrm{~cm}^{2} / \mathrm{c}[41,42]$ и $D(\mathrm{~N})=1.4 \cdot 10^{-4} \mathrm{~cm}^{2} / \mathrm{c}[43]$ соответственно. Поэтому скорость роста наностержней $\mathrm{GaN}$ в МСМЧК будет в первую очередь определяться скоростью диффузии атомов $\mathrm{Ga}$. Скорость диффузии атомов $\mathrm{Ga}$, рассчитанная по формуле $v \approx \sqrt{(D(\mathrm{Ga}) \cdot \tau)}$, где $\tau$ - время диффузии (c), составила 550 нм за 1 мин, что позволяет атомам Ga перемещаться в пределах всей сферической частицы, обеспечивая рост наностержней GaN. Наряду с диффузией атомов $\mathrm{Ga}$ и $\mathrm{N}$ в $\mathrm{SiO}_{2}$ имеет место диффузия атомов $\mathrm{Si}$ и $\mathrm{O}$ в $\mathrm{GaN}$ [44]. Данные процессы приводят к перераспределению материала внутри МСМЧК.

\section{4. Заключение}

В настоящей работе показано, что в результате гетерогенного синтеза $\mathrm{GaN}$ из $\mathrm{Ga}_{2} \mathrm{O}_{3}$ в термодинамически равновесных условиях посредством отжига при температуре $1300 \mathrm{~K}$ в атмосфере аммиака внутри МСМЧК образуются наностержни нитрида галлия. Размеры наностержней $\mathrm{GaN}$ отличаются от исходного размера мезопор (3.1 нм), и по данным ПЭМ их диаметр варьируется от 15 до $40 \mathrm{Hм}$, а длина от 50 до 150 нм. По данным рамановской спектроскопии, наностержни состоят из гексагонального GaN.

Предложен возможный механизм формирования наностержней $\mathrm{GaN}$, основанный на двух типах массопереноса вещества в МСМЧК: (1) переносе молекул газообразных компонентов посредством поверхностной диффузии, (2) переносе вещества за счет диффузии атомов $\mathrm{Ga}$ и $\mathrm{N}$ в аморфном $\mathrm{SiO}_{2}$. Рост наностержней $\mathrm{GaN}$ энергетически выгоден, и, по-видимому, формирование крупных наностержней $\mathrm{GaN}$ происходит за счет поглощения (исчезновения) мелких кристаллитов $\mathrm{GaN}$ в МСМЧК. 


\section{Благодарности}

Авторы работы благодарят А.Н. Смирнова за измерение рамановских спектров наностержней $\mathrm{GaN}$.

Измерения методом просвечивающей электронной микроскопии выполнены с использованием оборудования федерального ЦКП „Материаловедение и диагностика в передовых технологиях“ (ФТИ им. А.Ф. Иоффе).

\section{Финансирование работы}

Работа выполнена с использованием средств госбюджета по государственному заданию 0040-2019-0012.

\section{Конфликт интересов}

Авторы заявляют об отсутствии конфликта интересов.

\section{Список литературы}

[1] C.-C. Tsai, G.-H. Li, Y.-T. Lin, C.-W. Chang, P. Wadekar, Q. Y.S. Chen, L. Rigutti, M. Tchernycheva, F.H. Julien, L.-W. Tu. Nanoscale Res. Lett., 6, 631 (2011).

[2] D. Bimberg. Semiconductor Nanostructures (Springer, Berlin-Heidelberg, 2008).

[3] R. Agarwal, C.M. Lieber. Appl. Phys. A, 85, 209 (2006).

[4] C.M. Lieber, Z.L. Wang. MRS Bulletin, 32, 99 (2007).

[5] D. Ehrentraut, E. Meissner, M. Bockowski. Technology of gallium nitride crystal growth (Springer Verlag, BerlinHeidelberg, 2010).

[6] K. Kishino, H. Sekiguchi, A. Kikuchi. J. Cryst. Growth, 311, 2063 (2009).

[7] X.L. Chen, J.Y. Li, Y.G. Cao, Y. Lan, H. Li, M. He, C. Wang, Z. Zhang, Z. Qiao. Adv. Mater., 12, 1432 (2000).

[8] J.C. Johnson, H.J. Choi, K.P. Knutsen, R.D. Schaller, P. Yang, R.J. Saykally. Nature Materials, 1, 106 (2002).

[9] X.F. Duan, C.M. Lieber. J. Amer. Chem. Soc., 122, 188 (2000).

[10] D.K.T. Ng, L.S. Tan, M.H. Hong. Curr. Appl. Phys., 6, 403 (2006).

[11] K.A. Bertness, A. Roshko, L.M. Mansfield, T.E. Harvey, N.A. Sanford. J. Cryst. Growth, 300, 94 (2007).

[12] M. Tchernycheva, C. Sartel, G. Cirlin, L. Travers, G. Patriarche, J.-C. Harmand, L.S. Dang, J. Renard, B. Gayral, L. Nevou, F. Julien. Nanotechnology, 18, 385306 (2007).

[13] J.-W. Jao, Y.-F. Zhang, Y.-H. Li, C. Su, X.-M. Song, H. Yan, R.-Z. Wang. Sci. Reports, 5, 17692 (2015).

[14] G. Suo, S. Jiang, J. Zhang, J. Li, M. He. Adv. Condens. Matter. Physics, 2014, 456163 (2014).

[15] А.Н. Семенов, Д.В. Нечаев, С.И. Трошков, А.В. Нащекин, П.Н. Брунков, В.Н. Жмерик, С.В. Иванов. ФТП, 52, 1663 (2018).

[16] H. Parala, A. Devi, W. Rogge, A. Birkner, R.A. Fischer. J. Phys. IV France, 11, 473 (2001).

[17] C.T. Yang, M.H. Huang. J. Phys. Chem. B, 109, 17842 (2005).

[18] K. Dimos, L. Jankovi, I.B. Koutselas, M.A. Karakassides, R. Zboril, P. Komadel. J. Phys. Chem. C, 116, 1185 (2012).

[19] Е.Ю. Трофимова, Д.А. Курдюков, Ю.А. Кукушкина, М.А. Яговкина, В.Г. Голубев. Физика и химия стекла, $\mathbf{3 7}$, 38 (2011).
[20] E.Yu. Trofimova, D.A. Kurdyukov, S.A. Yakovlev, D.A. Kirilenko, Yu.A. Kukushkina, A.V. Nashchekin, A.A. Sitnikova, M.A. Yagovkina, V.G. Golubev. Nanotechnology, 24, 155601 (2013).

[21] Е.Ю. Стовпяга, Д.А. Курдюков, Ю.А. Кукушкина, В.В. Соколов, М.А. Яговкина. Физика и химия стекла, 41, 424 (2015).

[22] Е.Ю. Стовпяга, Д.А. Еуров, Д.А. Курдюков, А.Н. Смирнов, M.А. Яговкина, В.Ю. Григорьев, В.В. Романов, D.R. Yakovlev, В.Г. Голубев. ФТТ, 59, 1598 (2017).

[23] Д.А. Курдюков, Д.А. Еуров, Е.Ю. Стовпяга, С.А. Яковлев, Д.А. Кириленко, В.Г. Голубев. ФТТ, 56, 995 (2014).

[24] Д.А. Курдюков, Н.А. Феоктистов, Д.А. Кириленко, А.Н. Смирнов, В.Ю. Давыдов, В.Г. Голубев. ФТП, 53, 1068 (2019).

[25] Д.А. Курдюков, Д.А. Еуров, Е.Ю. Стовпяга, Д.А. Кириленко, С.В. Коняхин, А.В. Швидченко, В.Г. Голубев. ФТТ, 58, 2454 (2016).

[26] Е.Ю. Стовпяга, Д.А. Еуров, Д.А. Курдюков, А.Н. Смирнов, M.A. Яговкина, D.R. Yakovlev, В.Г. Голубев. ФТП, 52, 1000 (2018).

[27] D.A. Kurdyukov, D.A. Eurov, D.A. Kirilenko, J.A. Kukushkina, V.V. Sokolov, M.A. Yagovkina, V.G. Golubev. Micro. Mesopor. Mater., 223, 225 (2016).

[28] V.Yu. Davydov, Yu.E. Kitaev, I.N. Goncharuk, A.N. Smirnov, J. Graul, O. Semchinova, D. Uffmann, M.B. Smirnov, A.P. Mirgorodsky, R.A. Evarestov. Phys. Rev. B, 58, 12899 (1998).

[29] V.Yu. Davydov, R.E. Dunin-Borkovski, V.G. Golubev, J.L. Hutchison, N.F. Kartenko, D.A. Kurdyukov, A.B. Pevtsov, N.V. Sharenkova, J. Sloan, L.M. Sorokin. Semicond. Sci. Technol., 16, L5 (2001).

[30] N.K. Thanh, N. Maclean, S. Mahiddine. Chem. Rev., 114, 7610 (2014).

[31] С.И. Садовников, А.И. Гусев. ФТТ, 60 (7), 1203 (2018).

[32] Ю.М. Петров. Кластеры и малые частицы (М., Наука, 1986).

[33] A.F. White, W. Mellvill. J. Am. Chem. Soc., 27, 373 (1905).

[34] D. Dirtu, L. Odochian, A. Pui, I. Humelnicu. Cent. Eur. J. Chem., 4, 666 (2006).

[35] H. Kiyono, T. Sakai, M. Takahashi, S. Shimada. J. Cryst. Growth, 312, 2823 (2010).

[36] K. Kachel, M. Korytov, D. Gogova, Z. Galazka, M. Albrecht, R. Zwierz, D. Siche, S. Golka, A. Kwasniewski, M. Schmidbauer, R. Fornari. Cryst. Eng. Commun., 14, 8536 (2012).

[37] D.-H. Kuo, W.-H. Wu. J. Electrochem. Soc., 156, K1 (2009).

[38] R. Fornanini. Single crystals of electronic materials (Woodhead Publishing, Elsevier, 2018).

[39] Г. Шеффер. Химические транспортные реакции (М., Мир, 1964).

[40] G.M. Gajiev, D.A. Kurdyukov, V.V. Travnikov. Nanotechnology, 17, 5349 (2006).

[41] A.H. van Ommen. J. Appl. Phys., 57, 15 (1985).

[42] A.S. Grove, O. Lkistiko, Jr. Sah, C.T. Sah. J. Phys. Chem. Solids, 25, 985 (1964).

[43] J. Kioseoglou, M. Katsikini, K. Termentzidis, I. Karakostas, E.C. Paloura. J. Appl. Phys., 121, 054301 (2017).

[44] R. Jakiela, A. Barcz, E. Dumiszewska, A. Jagoda. Phys. Status Solidi C, 3, 1416 (2006).

Редактор А.Н. Смирнов 


\title{
Formation of GaN nanorods \\ in monodisperse spherical mesoporous silica particles
}

\author{
E.Yu. Stovpiaga, D.A. Kurdyukov, D.A. Kirilenko, \\ V.G. Golubev \\ loffe Institute, \\ 194021 St. Petersburg, Russia
}

Abstract Gallium nitride nanorods with a $15-40 \mathrm{~nm}$ diameter and a $50-150 \mathrm{~nm}$ length have been synthesized in monodisperse spherical mesoporous silica particles (MSMSP) by hightemperature annealing the $\mathrm{Ga}_{2} \mathrm{O}_{3}$ precursor in ammonia. The template material $\left(a-\mathrm{SiO}_{2}\right)$ was selectively removed by etching the composite MSMSP/GaN particles in HF. The individual GaN nanorods were thus obtained. It is shown, that the size of GaN nanorods was much higher than the pore size of MSMSP (diameter $\sim 3 \mathrm{~nm}$, length $\sim 10 \mathrm{~nm}$ ). The possible mechanism of formation of $\mathrm{GaN}$ nanorods was proposed. Redistribution of material inside the composite particles MSMSP/GaN possibly occurred by surface diffusion of gaseous molecules in mesopores and by diffusion of $\mathrm{Ga}$ and $\mathrm{N}$ atoms in $a-\mathrm{SiO}_{2}$. 